\title{
Flower structures of black mulberry (Morus nigra) trees
}

\author{
Mehmet Akif Demirel (DD $1^{*}$, Kenan Y1ldı (D) 1* $^{*}$ \\ ${ }^{1}$ Tokat Gaziosmanpasa University, Faculty of Agriculture, Department of Horticulture, Tokat-Turkey
}

\begin{abstract}
This study investigated the flower structures of a black mulberry population in Tokat province and its surroundings. Of the investigated black mulberry trees of the population, $49 \%$ were identified as monoecious-male, $43 \%$ as dioecious-female, $5.7 \%$ as dioecious-male and $2.3 \%$ as monoecious-mixed. Generally, four stamens were identified in male flowers and especially in mixed catkins, 3 or 2 stamens were also identified in male flowers. Female flowers were composed of a long two-lobed stigma and an ovary. Catkin lengths of male flowers varied between 42.7-22.8 $\mathrm{mm}$ and catkin lengths of female flowers varied between 24.1-4.3 mm. The number of male flowers per catkin varied between 26.36-10.62 in dioecious trees and 26.3-14.1 in monoecious trees. The number of female flowers per catkin varied between 36.16-13.5 in monoecious trees and between 52.0-15.6 in dioecious trees. There were significant differences in the phenological stages of the flowers. Flowering lasted about 60 days in all genotypes.
\end{abstract}

\section{ARTICLE HISTORY}

Received: 2 November 2021

Accepted: 29 November 2021

\section{KEYWORDS}

Black Mulberry

Flower

Catkin

Monoecious

Dioecious

\section{* CORRESPONDING}

mehmetakifdemirel60@gmail.com kenan.yildiz@gop.edu.tr

\section{Introduction}

There are several different mulberry species around the world and the most widely cultivated ones include black mulberry (Morus nigra), white mulberry (Morus alba) and red mulberry (Morus rubra) (De Candolle, 1967). The potential growth of various mulberry species in several regions of the world with different climates indicates quite a high adaptation capacity of the mulberry species (Zhang et al., 1998). With this high adaptation capacity, mulberries are widespread in tropics, sub-tropics and temperate zones of Asia, Europe, North and South America (Özgen et al., 2009). Among mulberry species, black mulberry with delicious fruits, high phenolics and pharmaceutical effects is prominent in different sectors (Anşin and Özkan, 1993; Gökmen, 1973). Black mulberry is an important plant with medical characteristics, thus commonly used in both modern and traditional medicine. Since the Roman and Greek era, black mulberry fruits, leaves and roots have been used in traditional medicine (Datta, 2002).

In Turkey, mulberry studies are primarily composed of selection studies conducted to bring out the prominent individuals in fruit characteristics from the natural populations of different regions (Y1lmaz et al., 2012). However, especially in India, collection orchards have been established with different mulberry species collected from different regions of the world and hybridization studies have been conducted between them (Das and Krishnaswami, 1965; Dwivedi et al., 1989; Tikader and Dandin, 2007). To utilize available quite a rich genetic source, besides selection studies, large-scale breeding programs with different breeding methods should be carried out also in Turkey. To that end, initially, flower structures and pollination biology of mulberries should be investigated in detail. On the other hand, the primary target in fruit culture is to get abundant and quality yield. Thus, the structure of the flower, constituting the origin of the fruit, should be well-known in plants grown for fruit.

There are a limited number of studies conducted on flower structure of mulberries. The majority of them have been conducted on white mulberry. Black mulberry has increasingly been produced in both the world and Turkey. However, there are not many studies conducted on flower structure and pollination biology of black mulberry. Therefore, the present study was designed to investigate the flower structure of mulberry genotypes of Tokat province with a significant mulberry population.

\section{Materials and methods}

\subsection{Materials}

The mulberry population available in Tokat province, towns and districts was used as the primary material of the present study.

\subsection{Methods}

Initially, flower structures and genders of population trees were investigated and trees were grouped based on identified flower structures and the ratio of these groups within the population was determined. Simultaneously, phenological data were recorded for 31 genotypes selected from the 
population. In phenological observations, bud swell (the data at which brown scales covering the buds opened and green color is started to be seen), initial flowering (the period in which first flowers are seen in a cluster) and post-bloom were determined (Figure 1).

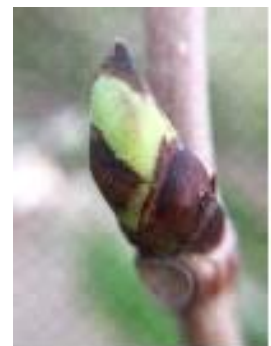

a

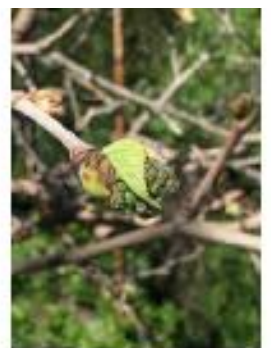

b

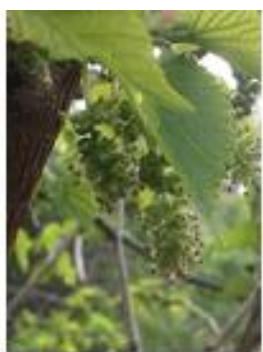

Figure 1. Phenological stages of black mulberry flowers a) Bud swell, b) Initial flowering c) Post-bloom

Different flower structures of mulberry trees of the relevant population were investigated and imaged. Peduncle length of a catkin, catkin length, catkin width and the number of flowers per catkin were determined in 11 monoecious, 11 dioecious female and two dioecious, male trees. Also, stigma length was measured in female flowers and anther and filament lengths were measured in male flowers. In a monoecious-hermaphrodite tree, peduncle length of a catkin, catkin length, catkin width, number of male flowers per catkin, number of female flowers per catkin, anther length, filament length and stigma lengths were measured.

\section{Results and discussions}

\subsection{Gender status of mulberry trees}

Investigated mulberry trees were divided into four different groups based on the gender of flowers they bear. The first group of trees was dioecious-male and they had only male catkins. The second group of trees was dioecious-female and they had only female catkins. The third group was composed of monoecious trees and they had both female and male catkins. The fourth group was composed of trees with only male or female catkins on the same tree besides both male and female flowers in the same catkin. In previous studies investigating the flower structure of mulberry, such flowers were so called as mixed (Jaiswal and Kumar, 1981).

Of 122 trees of the present population, 60 trees were monoecious, 52 trees were dioecious with female catkin, seven trees were dioecious with male catkin and three trees had mixed catkins. Tikader et al. (1995) studied different mulberry species and identified $56 \%$ of investigated trees as female, $31.3 \%$ as monoecious and $12 \%$ as male.

\subsection{Morphological structure of the flowers}

In the present study, mulberry trees forming only male flowers and not bearing female flowers were defined as dioecious-male. Dioecious-male genotypes constituted the minor portion of the investigated population. Images of male flowers are presented in Figure 2. Koyuncu and Vural (2003) investigated morphological characteristics of black mulberry trees and reported four stamens in a single flower. Similarly, in the present study, generally, four stamens were identified in male flowers and especially in mixed catkins, 3 or 2 stamens were also identified in male flowers.

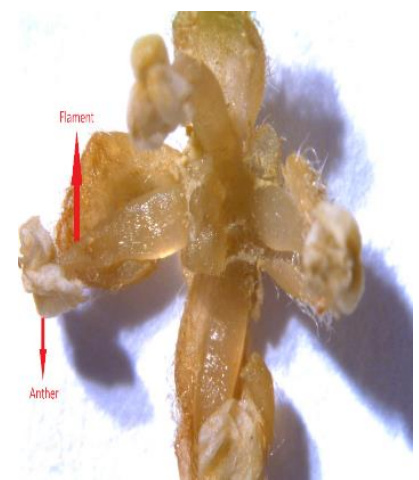

(a)

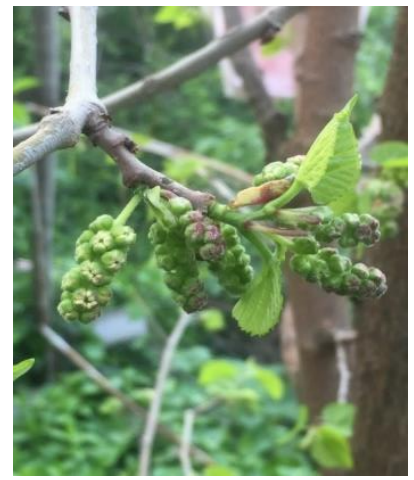

(c)

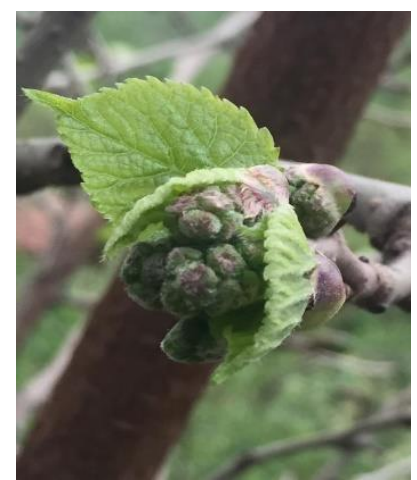

(b)

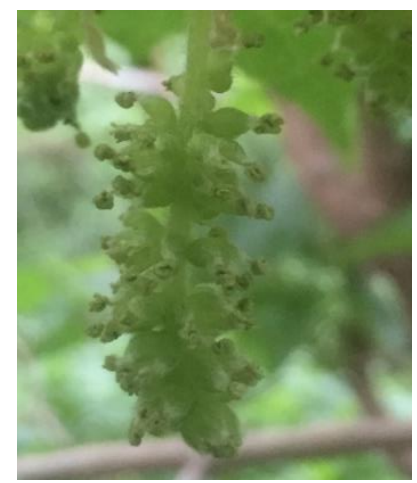

(d)
Figure 2. Male flowers a) Microscopic image of a single male flower b) Emergence of male catkin from the bud, c) Male flowers on branch d) Pollinated male flowers

Morphological data for flowers of two dioecious-male genotypes are provided in Table 1. While similar catkin peduncle lengths and catkin widths were seen in both genotypes, catkin length and number of flowers per catkin values were greater in Genotype 5. Longer catkins and a resultant greater number of flowers per catkin increase the value of the genotype as a pollinator.

Table 1. Morphological characteristics of flowers of dioecious-male genotypes

\begin{tabular}{lccccc}
\hline Genotype & $\begin{array}{c}\text { Peduncle length } \\
(\mathrm{mm})\end{array}$ & $\begin{array}{c}\text { Catkin length } \\
(\mathrm{mm})\end{array}$ & $\begin{array}{c}\text { Catkin width } \\
(\mathrm{mm})\end{array}$ & $\begin{array}{c}\text { Number of male } \\
\text { flowers }\end{array}$ & $\begin{array}{c}\text { Anther length } \\
(\mathrm{mm})\end{array}$ \\
\hline Genotype 5 & $10 \pm 0.78$ & $42.50 \pm 1.48$ & $6.25 \pm 0.34$ & $26.36 \pm 1.09$ & $1,44 \pm 0.08$ \\
Genotype 28 & $8.24 \pm 0.75$ & $19.88 \pm 1.19$ & $5.35 \pm 0.27$ & $10.62 \pm 0.87$ & $1.72 \pm 0.07$ \\
\hline
\end{tabular}


Morphological characteristics of male flowers of monoecious trees are provided in Table 2. Catkin peduncle lengths varied between $11.32-5.31 \mathrm{~mm}$. Similarly, catkin lengths also varied with the genotypes. Catkin length was measured as $42.7 \mathrm{~mm}$ in Genotype 2 and $22.8 \mathrm{~mm}$ in Genotype 1. Present findings comply with Ahlawat et al. (2016) reported for black mulberries grown in India. It was reported that catkin lengths varied between $2-4 \mathrm{~cm}$. Catkin lengths of the genotypes were similar to each other. There were significant differences in the number of male flowers per catkin of the genotypes. The number of male flowers was identified as 14.2 in Genotype 1 and 24.3 in Genotype 2. Anther lengths of male flowers of 11 monoecious genotypes varied between 1.19 and 1.83 $\mathrm{mm}$; filament lengths varied between 1.93 and 2.70 $\mathrm{mm}$. There is no information in the literature about anther or filament length of black mulberry flowers. However, anther lengths of another mulberry species (M. laevigata) were reported as between 0.9-1.16 mm (Tikader and Kamble, 2008).

The structure of female flowers of black mulberry genotypes is presented in Figure 3. The structure of a single flower is presented in Figure 3a. As can be inferred from the figure, the flower was composed of a two-lobed stigma, a short style and an ovary. Koyuncu et al. (2004) conducted a study on the black mulberry population of Isparta province. They reported that female flowers of black mulberry had a two-lobed stigma and the stigma connected to the ovary through a short style. Ahlawat et al. (2016) conducted a study on Indian black mulberry genotypes. They indicated that female flowers were composed of a two-lobed hairy stigma connected to the ovary through a subtle style. The flowers on catkin ready for pollination are presented in Figure $3 b$ and pollinated female catkins are presented in Figure 3c. As can be inferred from the figure, female catkins were tighter and shorter than male catkins. Similar findings were also reported by Koyuncu et al. (2004).

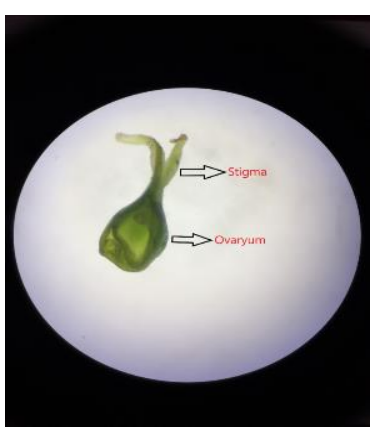

(a)

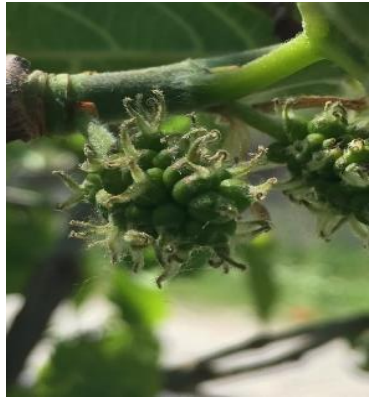

(c)

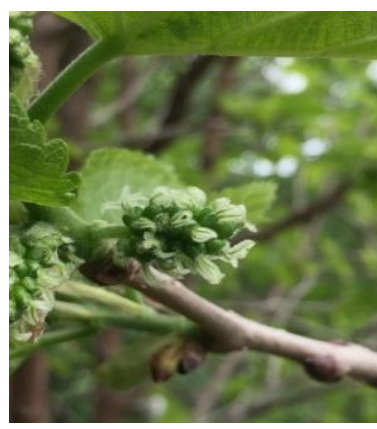

(b)

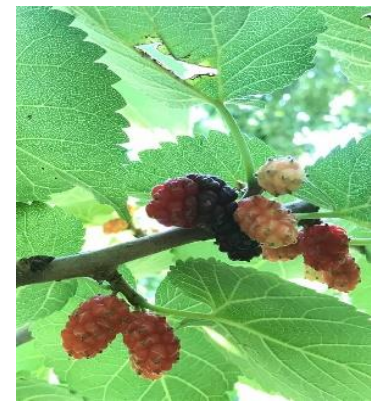

(d)
Figure 3. Images of female flowers a) Microscopic image of a single female flower, b) Female flowers on branch, c) Pollinated female flowers, d) Conversion of female flowers into fruit

Morphological characteristics of female flowers of monoecious trees are provided in Table 3. Peduncle lengths of female catkins varied between $1.36 \mathrm{~mm}$ (Genotype 16) and $5.74 \mathrm{~mm}$ (Genotype 1). Catkin lengths of female flowers of monoecious trees varied between 9.18-8.21 $\mathrm{mm}$ and catkin widths varied between 7.72-4.6 mm. There were remarkable differences in the number of female flowers per catkin of the genotypes. The average length of female catkins was measured as $13.5 \mathrm{~mm}$ in Genotype 16 and $36.16 \mathrm{~mm}$ in Genotype 1. Regarding the stigma length of female flowers, Genotype 1 and Genotype 2 were clearly differentiated from the others and had flowers with longer stigma lengths.

Table 2. Morphological characteristics of male flowers of monoecious genotypes

\begin{tabular}{lcccccc}
\hline Genotype & $\begin{array}{c}\text { Peduncle length } \\
(\mathrm{mm})\end{array}$ & $\begin{array}{c}\text { Catkin } \\
\text { length }(\mathrm{mm})\end{array}$ & $\begin{array}{c}\text { Catkin width } \\
(\mathrm{mm})\end{array}$ & $\begin{array}{c}\text { Number of } \\
\text { male flowers }\end{array}$ & $\begin{array}{c}\text { Anther length } \\
(\mathrm{mm})\end{array}$ & $\begin{array}{c}\text { Filament length } \\
(\mathrm{mm})\end{array}$ \\
\hline Genotype 1 & $7.92 \pm 0.72$ & $22.8 \pm 1.98$ & $7.04 \pm 0.36$ & $14.2 \pm 2.23$ & $1.42 \pm 0.09$ & $2.11 \pm 0.21$ \\
Genotype 2 & $11.32 \pm 0.99$ & $42.7 \pm 2.27$ & $8.21 \pm 0.25$ & $24.3 \pm 1.30$ & $1.19 \pm 0.08$ & $1.93 \pm 0.14$ \\
Genotype 13 & $9.41 \pm 1.03$ & $34.4 \pm 3.37$ & $7.62 \pm 0.25$ & $24.2 \pm 1.55$ & $1.59 \pm 0.11$ & $2.49 \pm 0.20$ \\
Genotype 7 & $7.19 \pm 0.35$ & $28.9 \pm 1.29$ & $7.42 \pm 0.32$ & $20.5 \pm 1.09$ & $1.47 \pm 0.07$ & $2.04 \pm 0.13$ \\
Genotype 14 & $6.83 \pm 0.54$ & $28.0 \pm 1.51$ & $6.72 \pm 0.28$ & $19.5 \pm 1.03$ & $1.43 \pm 0.09$ & $2.13 \pm 0.16$ \\
Genotype 16 & $7.16 \pm 1.27$ & $26.4 \pm 2.38$ & $7.80 \pm 0.49$ & $21.3 \pm 1.67$ & $1.32 \pm 0.08$ & $2.36 \pm 0.15$ \\
Genotype 27 & $8.57 \pm 1.24$ & $27.1 \pm 1.90$ & $6.38 \pm 0.67$ & $19.1 \pm 1.56$ & $1.48 \pm 0.03$ & $1.94 \pm 0.09$ \\
Genotype 22 & $5.31 \pm 0.58$ & $23.9 \pm 1.32$ & $5.00 \pm 0.03$ & $20.25 \pm 1.08$ & $1.63 \pm 0.09$ & $2.65 \pm 0.09$ \\
Genotype 10 & $7.29 \pm 0.69$ & $30.7 \pm 1.59$ & $6.53 \pm 0.32$ & $23.4 \pm 1.50$ & $1.83 \pm 0.22$ & $2.70 \pm 0.22$ \\
Genotype 8 & $9.34 \pm 0.80$ & $28.4 \pm 1.96$ & $6.44 \pm 0.21$ & $26.3 \pm 1.27$ & $1.40 \pm 0.06$ & $1.95 \pm 0.07$ \\
Genotype 4 & $8.26 \pm 0.79$ & $30.5 \pm 1.50$ & $6.28 \pm 0.30$ & $25.7 \pm 1.44$ & $1.62 \pm 0.06$ & $2.29 \pm 0.10$ \\
\hline
\end{tabular}


Table 3. Morphological characteristics of female flowers of monoecious genotypes

\begin{tabular}{lccccc}
\hline Genotype & $\begin{array}{c}\text { Peduncle length } \\
(\mathrm{mm})\end{array}$ & $\begin{array}{c}\text { Catkin length } \\
(\mathrm{mm})\end{array}$ & $\begin{array}{c}\text { Catkin width } \\
(\mathrm{mm})\end{array}$ & $\begin{array}{c}\text { Number of female } \\
\text { flowers }\end{array}$ & $\begin{array}{c}\text { Stigma length } \\
(\mathrm{mm})\end{array}$ \\
\hline Genotype 1 & $5.74 \pm 0.26$ & $19.18 \pm 0.75$ & $7.72 \pm 0.18$ & $36.16 \pm 1.17$ & $3.08 \pm 0.15$ \\
Genotype 2 & $5.02 \pm .043$ & $15.71 \pm 0.95$ & $6.66 \pm 0.18$ & $27.11 \pm 1.75$ & $3.02 \pm 0.17$ \\
Genotype 13 & $3.03 \pm 0.51$ & $12.22 \pm 0.94$ & $6.44 \pm 0.23$ & $28.11 \pm 2.55$ & $1.80 \pm 0.13$ \\
Genotype 7 & $2.73 \pm 0.31$ & $11.14 \pm 0.56$ & $5.68 \pm 0.17$ & $21.46 \pm 0.80$ & $1.33 \pm 0.10$ \\
Genotype 14 & $5.05 \pm .0 .60$ & $18.16 \pm 1.78$ & $7.65 \pm 0.49$ & $27.81 \pm 2.03$ & $1.36 \pm 0.09$ \\
Genotype 16 & $1.36 \pm 0.37$ & $8.21 \pm 0.19$ & $6.12 \pm 0.19$ & $13.50 \pm 0.50$ & $1.85 \pm 0.68$ \\
Genotype 27 & $3.56 \pm 0.33$ & $11.49 \pm 1.04$ & $5.78 \pm 0.80$ & $17.25 \pm 2.78$ & $1.37 \pm 0.13$ \\
Genotype 22 & $3.19 \pm 0.24$ & $11.21 \pm 0.53$ & $6.40 \pm 0.21$ & $23.16 \pm 1.56$ & $2.71 \pm 0.09$ \\
Genotype 10 & $4.63 \pm 0.45$ & $16.30 \pm 0.76$ & $7.36 \pm 0.17$ & $33.63 \pm 1.53$ & $2.18 \pm 0.18$ \\
Genotype 8 & $3.74 \pm 0.63$ & $11.26 \pm 1.73$ & $4.60 \pm 0.46$ & $27.75 \pm 2.72$ & $1.50 \pm 0.07$ \\
Genotype 4 & $5.58 \pm 0.43$ & $16.99 \pm 0.80$ & $7.28 \pm 0.26$ & $29.00 \pm 1.61$ & $1.86 \pm 0.09$ \\
\hline
\end{tabular}

In the present study, the black mulberry trees forming only female flowers and not bearing male flowers were defined as dioecious-female. Dioecious-female genotypes constituted the second greatest portion of the investigated population after monoecious genotypes. Morphological characteristics of flowers of dioecious-female genotypes are provided in Table 4. Genotype 26 was significantly different from the others and had greater values in terms of catkin peduncle length and catkin length. Catkin widths of the genotypes were generally similar to each other. There were remarkable differences in the number of flowers per catkin of the genotypes. Besides Genotype 26, Genotype 29 also had greater number of flowers per catkin. Koyuncu and Vural (2003) worked on black mulberry and reported average catkin length as $1.85 \mathrm{~cm}$, catkin width as $1.04 \mathrm{~cm}$ and the number of flowers per catkin as 33. Similar findings were observed in the present study, but Genotype 26 had a greater catkin length $(24.1 \mathrm{~mm})$ and the number of flowers per catkin $(52.0 \mathrm{~mm})$. Longer catkin and more flowers per catkin result in larger fruits, thus making these genotypes prominent in selection breeding. There were differences in the stigma lengths of the genotypes. The most extended stigma lengths were observed in Genotype 3 and Genotype 11 and the shortest in Genotype 29. Stigma length provides an advantage to the tree in pollination.

It was reported in a study conducted in India that besides the catkins composed only of male or female flowers in black mulberries, there were also flower structures with both male and female flowers in the same catkin or hermaphrodite flowers besides female flowers in the same catkin or hermaphrodite flowers besides male flowers in the same catkin (Jaiswal and Kumar, 1980). In the present study conducted with the black mulberry population of Tokat province, besides the catkins composed only of female or male flowers, there were a few trees with both flower genders. In the present study, hermaphrodite flower structure was not encountered. The mixed catkin and fruits of these flowers are presented in Figure 4. As can be inferred from the figure, besides female flowers, there were also male flowers in the same catkin. In these catkins, female flowers develop and form the fruits. Since the section including male flowers is not well-developed, misshaped fruits are then encountered.
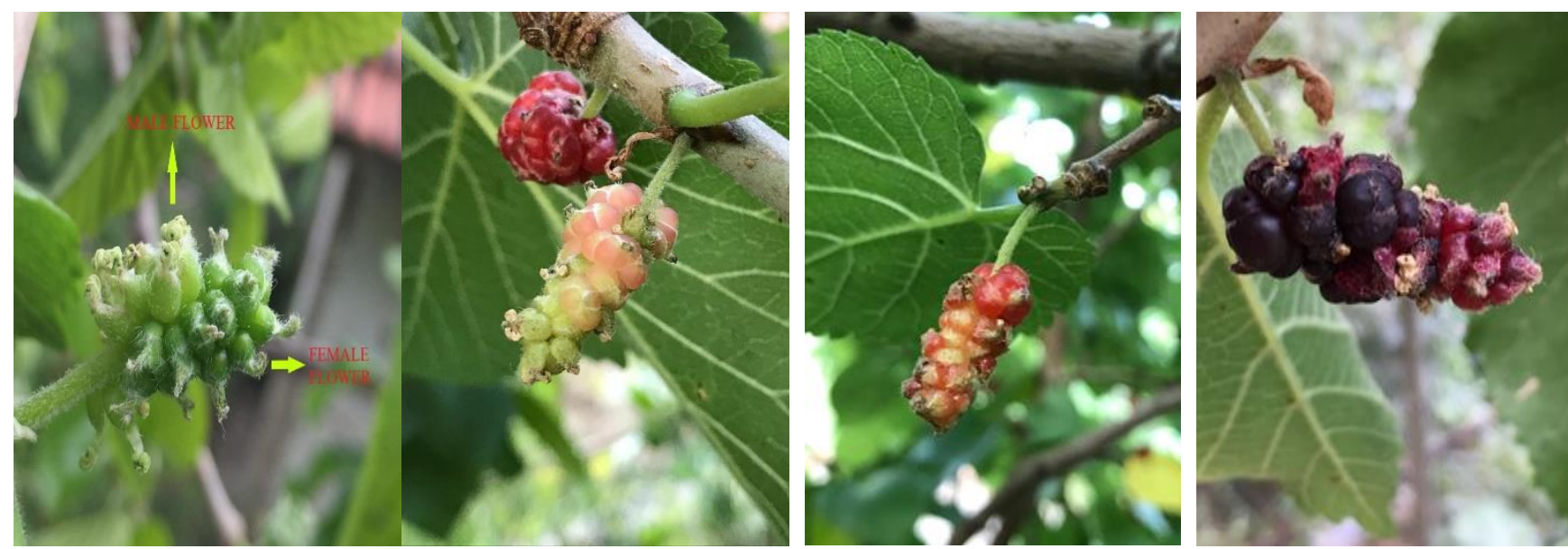

Figure 4. Mixed flower structure and resultant black mulberry fruits 
Table 4. Morphological characteristics of flowers of dioecious-female genotypes

\begin{tabular}{lccccc}
\hline Genotype & $\begin{array}{c}\text { Peduncle length } \\
(\mathrm{mm})\end{array}$ & $\begin{array}{c}\text { Catkin length } \\
(\mathrm{mm})\end{array}$ & $\begin{array}{c}\text { Catkin width } \\
(\mathrm{mm})\end{array}$ & $\begin{array}{c}\text { Number of female } \\
\text { flowers }\end{array}$ & $\begin{array}{c}\text { Stigma length } \\
(\mathrm{mm})\end{array}$ \\
\hline Genotype 3 & $5.03 \pm 0.39$ & $18.16 \pm 1.31$ & $7.35 \pm 0.32$ & $31.40 \pm 1.85$ & $3.31 \pm 0.13$ \\
Genotype 6 & $3.93 \pm 0.56$ & $16.10 \pm 1.30$ & $6.76 \pm 0.39$ & $32.30 \pm 1.87$ & $2.04 \pm 0.09$ \\
Genotype 9 & $2.88 \pm 0.35$ & $10.34 \pm 0.90$ & $5.69 \pm .022$ & $15.60 \pm 2.27$ & $2.19 \pm 0.17$ \\
Genotype 23 & $5.41 \pm 0.39$ & $16.52 \pm 1.00$ & $7.01 \pm 0.41$ & $24.16 \pm 1.99$ & $2.65 \pm 0.10$ \\
Genotype 29 & $6.78 \pm 0.47$ & $17.52 \pm 1.08$ & $6.95 \pm 0.31$ & $47.42 \pm 3.27$ & $1.46 \pm 0.07$ \\
Genotype 11 & $3.29 \pm 0.22$ & $10.94 \pm 0.29$ & $5.26 \pm 0.29$ & $18.00 \pm 0.85$ & $3.29 \pm 0.13$ \\
Genotype 12 & $3.99 \pm 0.37$ & $12.32 \pm 0.69$ & $5.62 \pm 0.23$ & $20.41 \pm 1.88$ & $2.50 \pm 0.10$ \\
Genotype 25 & $4.00 \pm 0.29$ & $12.49 \pm 0.48$ & $6.09 \pm 0.21$ & $23.36 \pm 1.50$ & $2.48 \pm 0.12$ \\
Genotype 18 & $4.04 \pm 0.22$ & $13.73 \pm 0.74$ & $6.29 \pm 0.23$ & $25.76 \pm 1.35$ & $2.83 \pm 0.14$ \\
Genotype 21 & $4.30 \pm 0.25$ & $4.30 \pm 0.57$ & $6.66 \pm 0.26$ & $25.93 \pm 1.05$ & $2.60 \pm 0.08$ \\
Genotype 26 & $11.47 \pm 0.98$ & $24.10 \pm 1.59$ & $7.78 \pm 0.34$ & $52.00 \pm 3.72$ & $1.76 \pm 0.12$ \\
\hline
\end{tabular}

There were a few trees with mixed flower structures in the present population. The morphological characteristics of the flowers taken from a healthy one are provided in Table 5.
In the present mixed catkins. there was an average of 21.83 female flowers and 6.33 male flowers.

Table 5. Morphological characteristics of the flowers of monoecious-mixed genotype

\begin{tabular}{|c|c|c|c|c|c|c|c|c|c|}
\hline Genotype & $\begin{array}{c}\text { Peduncle } \\
\text { length } \\
(\mathrm{mm})\end{array}$ & $\begin{array}{l}\text { Catkin length } \\
(\mathrm{mm})\end{array}$ & $\begin{array}{l}\text { Catkin width } \\
(\mathrm{mm})\end{array}$ & $\begin{array}{l}\text { Number } \\
\text { of male } \\
\text { flowers }\end{array}$ & $\begin{array}{c}\text { Number } \\
\text { of female } \\
\text { flowers }\end{array}$ & $\begin{array}{l}\text { Anther } \\
\text { length } \\
(\mathrm{mm})\end{array}$ & $\begin{array}{c}\text { Filament } \\
\text { length } \\
(\mathrm{mm})\end{array}$ & $\begin{array}{l}\text { Number } \\
\text { of anthers }\end{array}$ & $\begin{array}{c}\text { Stigma } \\
\text { length } \\
(\mathrm{mm})\end{array}$ \\
\hline Genotype 2 & $8.8 \pm 1.7$ & $25.8 \pm 4.9$ & $6.79 \pm 0.1$ & $6.33 \pm 2.4$ & $21.8 \pm 2.7$ & $1.64 \pm 0.2$ & $2.38 \pm 0.5$ & $11.7 \pm 4.7$ & $2.65 \pm 0.2$ \\
\hline
\end{tabular}

\subsection{Phenological observations}

Bud swell, initial flowering and post-bloom dates of 31 genotypes were determined and relevant dates are provided in Table 6. The earlies bud swell was encountered in Genotype 31 (April 9) and the latest bud swell was encountered in Genotype 20 (April 20). Koyuncu et al. (2004) studied black mulberries and reported bud swelling dates between April 20-30. The initial flowering was encountered on May 1 in early genotypes and on May 8 in late genotypes. The earliest post-bloom was encountered in Genotype 22 (May 29) and the latest in Genotype 28 (July 9). Flowering lasted about 60 days in all genotypes. Such a case indicated that black mulberry had an advantage of not being influenced by late spring frosts compared to various other fruit species.

\section{Conclusion}

Present findings revealed that there were genotypes with different flower structures in investigated population. The majority of the black mulberry trees were monoecious or dioecious-female. but there were also a few dioecious-male or monoecious-mixed trees in the population. Present findings may have significant contributions to further black mulberry breeding programs. Further research is recommended for detailed investigation of pollination and resultant fruit set and development of black mulberries. Such knowledge gained from the present study and prospective future studies will lead to better black mulberry orchards.

\section{Compliance with Ethical Standards}

\section{Conflict of Interest}

The authors have no conflict of interest to declare.

\section{Authors' Contributions}

Mehmet Akif Demirel: Methodology. Investigation. Conceptualization. Validation. Writing - original draft. Visualization. Kenan Yıldız: Methodology. Investigation. Conceptualization. Validation. Writing - original draft. Visualization. Data curation.

\section{Ethical approval}

Not applicable.

\section{Funding}

No financial support was received for this study.

\section{Data availability}

Not applicable.

\section{Consent for publication}

Not applicable. 
Table 6. Phenological observations of the specified genotypes

\begin{tabular}{|c|c|c|c|c|}
\hline Genotype & Gender & Bud swell & Initial flowering & Post-bloom \\
\hline Genotype 1 & Monoecious & 13.04 .2019 & 2.05 .2019 & 30.06 .2019 \\
\hline Genotype 2 & Monoecious-Mixed & 12.04 .2019 & 30.04 .2019 & 5.07.2019 \\
\hline Genotype 3 & Dioecious-Female & 16.04 .2019 & 1.05 .2019 & 30.06 .2019 \\
\hline Genotype 4 & Monoecious & 16.04 .2019 & 5.05 .2019 & 30.06 .2019 \\
\hline Genotype 5 & Dioecious-Male & 14.04.2019 & 5.05 .2019 & 2.07.2019 \\
\hline Genotype 6 & Dioecious-Female & 12.04 .2019 & 5.05 .2019 & 30.06 .2019 \\
\hline Genotype 7 & Monoecious & 14.04.2019 & 5.05 .2019 & 2.07.2019 \\
\hline Genotype 8 & Monoecious & 19.04.2019 & 8.05 .2019 & 4.07.2019 \\
\hline Genotype 9 & Dioecious-Female & 19.04.2019 & 8.05 .2019 & 08.07.019 \\
\hline Genotype 10 & Monoecious & 19.04.2019 & 8.05 .2019 & 4.07.2019 \\
\hline Genotype 11 & Dioecious-Female & 19.04 .2019 & 8.05 .2019 & 4.07.2019 \\
\hline Genotype 12 & Dioecious-Female & 16.04 .2019 & 5.05 .2019 & 4.07.2019 \\
\hline Genotype 13 & Monoecious & 19.04.2019 & 8.05 .2019 & 4.07.2019 \\
\hline Genotype 14 & Monoecious & 16.04 .2019 & 5.05 .2019 & 2.07.2019 \\
\hline Genotype 15 & Dioecious-Female & 14.04.2019 & 1.05 .2019 & 30.06 .2019 \\
\hline Genotype 16 & Monoecious & 20.04.2019 & 7.05.2019 & 5.07.2019 \\
\hline Genotype 17 & Monoecious & 15.04 .2019 & 7.05 .2019 & 6.07 .2019 \\
\hline Genotype 18 & Dioecious-Female & 13.04.2019 & 6.05 .2019 & 6.07.2019 \\
\hline Genotype 19 & Monoecious & 16.04 .2019 & 1.05 .2019 & 29.06 .2019 \\
\hline Genotype 20 & Monoecious & 16.04 .2019 & 2.05 .2019 & 30.06 .2019 \\
\hline Genotype 21 & Dioecious-Female & 15.04 .2019 & 1.05 .2019 & 30.06 .2019 \\
\hline Genotype 22 & Dioecious-Female & 15.04 .2019 & 2.05 .2019 & 29.06.2019 \\
\hline Genotype 23 & Dioecious-Female & 16.04 .2019 & 5.05 .2019 & 3.07.2019 \\
\hline Genotype 24 & Monoecious & 13.04.2019 & 7.05 .2019 & 5.07 .2019 \\
\hline Genotype 25 & Dioecious-Female & 13.04 .2019 & 7.05 .2019 & 5.07 .2019 \\
\hline Genotype 26 & Dioecious-Female & 16.04 .2019 & 5.05 .2019 & 3.07 .2019 \\
\hline Genotype 27 & Monoecious & 14.04 .2019 & 6.05 .2019 & 3.07 .2019 \\
\hline Genotype 28 & Dioecious-Male & 12.04.2019 & 8.05 .2019 & 9.07.2019 \\
\hline Genotype 29 & Dioecious-Female & 11.04 .2019 & 6.05 .2019 & 5.07 .2019 \\
\hline Genotype 30 & Monoecious & 10.04 .2020 & 5.05 .2020 & 6.07 .2020 \\
\hline Genotype 31 & Monoecious & 09.04 .2020 & 8.05 .2020 & 8.07 .2020 \\
\hline
\end{tabular}

\section{References}

Ahlawat, T. R., Patel, N. L., Agnihotri, R., Patel, C. R., \& Tandel, Y. N. (2016). Black mulberry (Morus nigra). Underutilized Fruit Crops: Importance and Cultivation, 195-212.

Anşin, R., \& Özkan, Z. C. (1993). Seed Plants (Spermatophyta) Woody Taxa (in Turkish: Tohumlu Bitkiler (Spermatophyta) Odunsu Taksonlar). Black Sea Technical University Faculty of Forestry Publications, Trabzon, Turkey.

Das. B.C.. Krishnaswami. S. (1965). Some observations on interspecific hybridization in mulberry. Indian Journal of Sericulture, 4, 1-8.

Datta. R.K. (2002). Mulberry cultivation and utilization in india. Central Sericultural Research \& Training Institute. Central Silk Board, Srirampure, Mysore 570008. India.

De Candolle. A. (1967). Origin of cultivated plants. New york and london. p. 149-153.

Dwivedi. N.K.. Suryanarayana N.. Susheelamma. B.N.. Sikdar A.K.. \& Jolly. M.S. (1989). Interspecific hybridization studies in mulberry. Sericologia, 29, 147-149.

Gökmen. H. (1973). Angiosperms. 1. Chapter. şark printing press. Ankara.

Jaiswal, V. S., \& Kumar, A. (1981). Modification of sex-expression and fruit-formation on male plants of Morus nigra L. by chlorflurenol. Proceedings: Plant Sciences, 90(5), 395-400.

Jaiswal. V.S.. \& Kumar. A. (1980). Induction of male inflorescence on the female plants of Morus nigra L. by $\mathrm{GA}_{3}$. Indian Journal of Experimental Biology, 18, 911-913.
Koyuncu F.. Koyuncu. M.A.. Yıldırım. F.. \& Vural. E. (2004). Evaluation of black mulberry (Morus nigra 1.) genotypes from lakes region,Turkey. European Journal of Horticultural Science, 69 (3), 125-131.

Koyuncu. F.. \& Vural. E. (2003). Morphological characteristics of some organs and tissues of black mulberry (Morus nigra L.) tree. National Kiwi and Berries Symposium. 23-25 October 2003, pp. 418-423.

Tikader. A.. \& Dandin. S.B. (2007). Pre-breeding efforts to utilize two wild morus species. Current Science, 92,1072-1076.

Tikader. A.. \& Dandin. S.B. (2008). DNA fingerprint of inter and intraspecific hybrids from Morus species using RAPD. Geobios-Jodhpur, $35,113-120$

Tikader. A.. Vijayan. K.. Raghunath. M.K.. Chakraborti. S.P.. Roy. B.N.. \& Pavankumar. T. (1995). Studies on sexual variations in mulberry (Morus spp). Euphytica, 84,115-120.

Özgen. M.. Serce. S.. \& Kaya. C. (2009). Phytochemical and antioxidant properties of anthocyanin-rich Morus nigra and Morus rubra fruits. Scientia Horticulturae, 119, 275-279.

Yılmaz. K.U.. Zengin. Y.. Ercisli. S.. Demirtas. M.N.. Kan. T.. \& Nazli. A.R. (2012). Morphological diversity on fruit characteristics among some selected mulberry genotypes from Turkey. Journal of Animal and Plant Sciences, 22(1), 211-214.

Zhang. Y.. Chengfu. L.. Jinme1. Z.. Hongzi. Z.. \& Xiaomıng. X. (1998) Polymorphism studies on genomic DNA of diploids and poliploids in mulberry. Journal of Zheijang Agricultural University, 24, 79-81.

Copyright: C 2021 by the authors. Turkish Journal of Food and Agriculture Sciences is licensed under a Creative Commons AttributionNonCommercial-NoDerivatives 4.0 International License 